\title{
Asymmetric Information and Overinvestment in Quality
}

\author{
Paul Belleflamme \\ MARTIN PEITZ
}

CESIFO WORKING PAPER NO. 2619

CATEGORY 11: INDUSTRIAL ORGANISATION

APRIL 2009

Presented at CESifo Area Conference on ApPlied Microeconomics, March 2009

\footnotetext{
An electronic version of the paper may be downloaded

- from the SSRN website: Www.SSRN.com

- from the RePEc website: $\quad$ www.RePEc.org

- from the CESifo website: www.CESifo-group.org/wp
} 


\title{
Asymmetric Information and Overinvestment in Quality
}

\begin{abstract}
In a standard adverse selection world, asymmetric information about product quality leads to quality deterioration in the market. Suppose that a higher investment level makes the realization of high quality more likely. Then, if consumers observe the investment (but not the realization of product quality) before purchase, they can infer the probability distribution of high and low quality that may be put on the market. We uncover two effects that may lead the firm to overinvest in quality compared to a market with full information: first, an adverse selection effect according to which a sufficiently large investment can avoid adverse selection and, second, an efficiency effect according to which a larger investment reduces the probability of socially inefficient, low quality products in the market.
\end{abstract}

JEL Code: D82, D92, L15.

Keywords: asymmetric information, product quality.

Paul Belleflamme

CORE / Louvain School of Management

Catholic University of Louvain

34 Voie du Roman Pays

Belgium - 1348 Louvain la Neuve

Paul.Belleflamme@uclouvain.be
Martin Peitz

Department of Economics

University of Mannheim

68131 Mannheim

Germany

martin.peitz@googlemail.com

First version: October 2006. This version: March 2008

We received helpful comments from Joe Harrington, two anonymous referees and various seminar audiences. Peitz gratefully acknowledges financial support from the German Science Foundation (SFB TR 15). Both authors acknowledge CESifo sponsorship. 


\section{Introduction}

We examine the effects of asymmetric information on a firm's incentive to invest in the quality of its product. Asymmetric information prevails because consumers cannot ascertain the quality of the product before they buy it. Asymmetric information may then lead to adverse selection because a firm upon learning its type has the option to exit the market. Prior to learning its quality, the firm decides on a risky investment: a higher investment increases the probability that product quality is high. Consumers can observe the investment level and thereby, obtain information about the expected quality in the market. Using a simple model, we show that in such a situation, firms might end up investing more in quality under asymmetric information than under full information.

Inspired by previous work that alludes to the adverse selection problem arising from an unmodeled investment in quality (see, e.g., Milgrom and Roberts, 1986), we explicitly model that the level of the investment affects the probability distribution over quality and we provide two simple arguments that support overinvestment in quality. First, if it is sufficiently likely that the firm's quality is low, the expected willingness to pay of a consumer is less than the marginal cost of high quality (which is larger than the cost of low quality). In such a situation the high-quality firm would exit the market so that there is adverse selection. At the investment stage, the firm foresees this problem: it can overinvest compared to the full information benchmark to avoid adverse selection - we call this effect the adverse selection effect. Second, since a larger investment gives evidence of a probability distribution with a higher probability of high quality, incentives to invest are stronger under asymmetric information if low-quality production is socially inefficient, that is, if the unit cost of production exceeds the willingness-to-pay for this unit. Overinvestment (relative to full information, where inefficient products are not offered in the market) here serves to limit the probability of socially inefficient products being sold in the market — we call this effect the efficiency effect. Each effect on its own may lead to overinvestment under asymmetric information relative to the full information benchmark (which, in our benchmark model, implements the socially efficient allocation). 
Key requisite for our result is the consumers' ability to draw inferences from investment levels on expected product quality. Consumers can be informed about certain business practices and about the use of certain inputs. Concerning business practices, the type of investment we have in mind can be exemplified by a firm's effort to meet standards for quality management systems, such as ISO 9000. The ISO 9000 certification does not guarantee the quality of end products and services; rather, it certifies that consistent business processes are being applied. That is, it proves that the firm (actually, any type of organization) has put in place the necessary processes (i.e., a quality management system) "to fulfil the customer's quality requirements, and applicable regulatory requirements, while aiming to enhance customer satisfaction, and achieve continual improvement of its performance in pursuit of these objectives." ${ }^{1}$ Cole (1998, p. 68) confirms our view by suggesting that firms may make ISO 9000 "their primary instrument for signaling quality to their customers." ${ }^{2}$ ISO 9000 thus enables a firm to convince consumers that the probability of a failure is low; yet, it cannot exclude the possibility of a failure and thus applying ISO 9000 does not constitute a minimum standard on product quality.

Also, pharmaceutical firms provide information about their input in research and development for a particular prescription drug, apparently to make prescribing doctors and hospital pharmacists think that their product is likely to be successful (and thus justify high margins). In the cosmetics industry, the leading company, L'Oréal, emphasizes in its advertisement campaigns the large number of patents it files every year (over 500 in 2005) and how much it invests in cosmetic and dermatological research (3\% of sales or $\$ 625$ million in 2005), so as to convince consumers of its commitment to

\footnotetext{
${ }^{1}$ Taken from www.iso.org (ISO 9000. Understanding the basics).

${ }^{2}$ However, firms may also seek certification simply in compliance with requirements of major customers or regulators. To disentangle the relative importance of these two motivations, Anderson et al. (1999) estimate a probit model of ISO 9000 certification. They show that the signaling motivation is indeed important: the desirability of communicating quality outcomes to external parties provides incremental explanatory power for the certification decision (even after including compliance motivations for seeking certification). Quality management systems seem thus to correspond to the type of investments we refer to in our model.
} 
market high-quality products. Producers of wines, organic food and other food products invest in production processes and inform consumers about these investments with the idea that the adoption of such processes leads to better products on average. This information is often transmitted by the use of certain labels provided by producer organizations that guarantee specific production processes and inputs.

Concerning information about inputs, we note that in various industries products consist of a collection of inputs of uncertain quality. Let us take a particularly simple view on how product quality is determined: suppose consumers only care about price and the probability that the product is experienced to be of high quality; this probability is determined by the share of high-quality inputs. According to this view, the investment decision refers to the decision to which extent to procure high-quality components. Then by advertising the brands of some of the inputs, the firm informs consumers that the product's overall performance is likely to be good. ${ }^{3}$ Examples abound: equipment manufacturers use certified components (e.g. Leica lenses in optical equipment); bike manufacturers advertise the components produced e.g. by Shimano; Hollywood studios hire well-liked actors partly with the idea that these actors lead to better movies on average. Presuming that better actors make it more likely that consumers enjoy the movie, our theory suggests that studios overinvest in these well-liked actors when the adverse selection effect comes into play (even ignoring the competition at the box office). We may even link our theory to the response of hiring decisions by firms: a well-known CEO or CFO may be seen as a "branded" input that increases the likelihood of good performance and thus improves the conditions for external financing.

While there is an abundant economic literature on quality in asymmetric information situations, we are not aware of work that uncovers the adverse selection and efficiency effects described above. This literature starts with Akerlof's (1970) "lemons' principle", according to which adverse selection (resulting from asymmetric information) causes the bad quality to drive the good quality out of the market. Various ways have then been explored to

\footnotetext{
${ }^{3}$ According to this view, there is no signaling taking place. Signaling motives can be an alternative reason for the use of certified inputs if they are complements to each other.
} 
remedy, or at least alleviate, the underprovision of quality that prevails under asymmetric information. Warranties (see e.g. Grossman, 1981) and repeat purchase (see e.g. Klein and Leffler, 1981) may lead to socially optimal quality levels. Leland (1979) has explored the role of minimum quality standards as a policy to cope with the underprovision of quality in a competitive market. He also explores the incentives of a professional group to set a minimum industry quality standard. Here, a socially excessive minimum quality standard may result as a means to restrict supply and as a means to increase demand by affecting average quality. Note that Leland's arguments for excessive quality standards do not apply to our model. ${ }^{4}$

Signaling is another means by which firms may reduce the asymmetric information and convince consumers of the good quality of their product. Typically, in the signaling literature started by Spence (1973), an investment is non-productive but less costly for high-quality types. Spence shows that the non-productive investment can be used as a signaling device. ${ }^{5}$ In contrast with the signaling literature, the investment in our model is made before the type is known. ${ }^{6}$ Here, the level of investment determines the

\footnotetext{
${ }^{4}$ De Meza and Webb (1987) obtain an overinvestment result of a different sort. They consider a competitive market in which entrepreneurs face an asymmetric information problem when asking for outside finance. Entrepreneurs have to make the same level of investment to enter the market but they differ in the probability to be successful. De Meza and Webb show that too many entrepreneurs invest. In their model, the overinvestment result directly stems from the adverse selection framework that makes high-quality projects draw in low-quality projects. In a related model, Lensink and Sterken (2001) also obtain an overinvestment result, which, however, stems from the possibility to delay the investment decision and not from the heterogeneity of expected returns of projects. Yet, in these models more aggregate investment lowers average quality.

Levin (2001) considers different qualities of seller information in an Akerlof model and shows that the amount of trade and thus average quality are nonmonotone in the degree of asymmetric information. See also Kessler (2001).

${ }^{5}$ Other potential signals are price and advertising; see, e.g., the seminal contributions by Nelson (1974) and Milgrom and Roberts (1986). In a price-signaling context, Shieh (1993) has analyzed the investment incentives in cost-reducing innovations under asymmetric information, where neither the investment nor product quality is observable to consumers. He shows that asymmetric information about quality may strengthen the firm's incentive to invest in cost-reducing innovation.

${ }^{6}$ In a signaling context, Daughety and Reinganum (1995) develop a monopoly model in which $\mathrm{R} \& \mathrm{D}$ also affects the probability distribution over types and find that the firm
} 
probability distribution over types and thus directly provides information to consumers. We obtain overinvestment under asymmetric information compared to full information for the reasons explained above. These are different from the signaling argument. ${ }^{7}$

Creane (2007) considers a market in which an unlimited number of homogeneous firms decide whether to enter with uncertain quality. After entry, firms observe the quality; high quality is more costly than low quality. The number of firms, determined by the free entry condition according to which high and low quality firms stay in the market, is not sustainable because the participation constraint of high-quality firms is violated, and thus would lead to adverse selection. Therefore firms enter in smaller number and obtain positive equilibrium profits under free entry. While Creane considers entry for a given investment level, we analyze the situation for a given firm in which the probability distribution over quality is continuously affected by the investment level.

As outlined above, our paper provides new insights on the interaction between asymmetric information and investment. Our benchmark model has been stripped down to highlight the basic effects at work. As a downside, this does not allow us to address interesting policy questions. To this end, we extend the analysis to markets in which the firm is not able to extract the full expected surplus (as naturally arises in a bargaining context, as analyzed in Subsection 4.2, or with downward sloping demand, as analyzed in Subsection 4.3). In such markets, private and social incentives to invest already differ under full information. Our overinvestment result then implies that asymmetric information with respect to realized quality may improve welfare. Public policy interventions (such as consumer reports, or government approval of product introductions) often try to alleviate the asymmetric information problem consumers face about final product quality. Our results show that such policies may be harmful to society as they underinvests. While the firm can use price to signal quality, the R\&D level is unobservable to consumers and thus does not allow them to draw inferences, contrary to our setting.

${ }^{7}$ An advantage of our formulation relative to the signaling literature is that consumers obtain direct information, so that we do not need to be concerned with out-of-equilibium beliefs. 
may reduce investments.

The paper is organized as follows. In Section 2, we lay out the model and we analyze the benchmark of full information. In Section 3, we develop the asymmetric information case and we contrast it to the benchmark in order to establish our main result (which we illustrate through a numerical example). In Section 4, we provide a number of extensions: we reconsider the analysis introducing outside options, partial rent extraction, and heterogeneous consumers. We conclude in Section 5.

\section{The model and full-information benchmark}

\section{$2.1 \quad$ The model}

Suppose a single seller offers a product to a unit mass of buyers. The seller's opportunity cost is $c_{s}$, where $s \in\{L, H\}$ is the quality of the product. High quality is assumed to be more costly than low quality, $c_{H}>c_{L}$. There is a unit mass of buyers who are assumed to be identical and have unit demand. The valuation of each buyer is assumed to be $r_{s}$. By definition, high quality is more valuable than low quality, $r_{H}>r_{L}$. Denote $I(\lambda)$ the investment that is needed to obtain that with probability $\lambda$ the product is of high quality. Specifically, suppose that $I(\lambda)=(k / 2) \lambda^{2}$, which satisfies $I^{\prime}>0, I^{\prime \prime}>0$, and $\lim _{\lambda \rightarrow 0} I^{\prime}(\lambda)=0$.

We consider the following three-stage game: at stage 1 , the firm invests $I$ in quality; at stage 2, after learning the quality realization it sets its price; at stage 3 , buyers form beliefs about product quality and make their purchasing decision. As stated in the introduction, $I(\lambda)$ can be interpreted as efforts to meet standards for quality management systems, or as a commitment to meet on average a certain reliability or quality of the product. This is an upfront investment in the "design" of the product which does not affect the marginal cost. ${ }^{8}$ After quality has been realized, a firm with the ability to produce a certain quality level has to use variable inputs for production.

\footnotetext{
${ }^{8}$ Arguably, incorporating branded inputs into the product also affects marginal cost. In our specification, we stress the fixed-cost part of the contractual arrangement between input provider and firm. Our theory generalizes to variable costs that not only depend on the realization of quality but also on $\lambda$.
} 
These inputs are more costly for high than for low quality. ${ }^{9}$

As we will explore below, under full information the firm chooses a strictly positive investment level if $r_{H}-c_{H}>r_{L}-c_{L}$ and zero investment if the reverse inequality holds. Note that in our setting, the full-information solution implements the first best allocation (this is due to the fact that the firm fully extracts all surplus); thus, deviations from the first best are the result of asymmetric information.

If the quality choice and the underlying investment decision cannot be observed by consumers, the firm has no means to convince consumers that its product is of high quality; the firm will therefore invest zero. This confirms that in markets in which firms choose quality, firms tend to provide too low a quality from a social point of view.

What we investigate is whether a risky investment in quality, where the investment is observable to consumers, results in the same type of quality trap as before. Clearly, the situation we envisage now potentially allows consumers to obtain information about the expected quality in the market, since consumers observe the investment effort and have a clear understanding of the relationship between investment spending and expected quality. We restrict attention to equilibria in which the firm extracts all rents so that price is equal to expected surplus. ${ }^{10}$

To simplify the exposition, and with minimum loss of generality, we make the following set of assumptions:

(A1) $r_{H}>c_{H}$,

(A2) $r_{H}-c_{H}>r_{L}-c_{L}$,

(A3) $c_{H}>r_{L}$.

According to assumption (A1), the high quality is socially beneficial. We make no such assumption for the low quality; rather, we want to contrast

\footnotetext{
${ }^{9}$ Here, a moral hazard problem may arise according to which a high-ability producer deviates to low quality. We deal with this issue in the extension section.

${ }^{10}$ In a modified model in which the number of consumers exceeds the number of available units and in which consumers bid for the product, equilibrium price is necessarily equal to expected surplus (see e.g. Tadelis, 1999).
} 
the cases where the low quality is either socially beneficial $\left(r_{L}>c_{L}\right)$ or not $\left(r_{L}<c_{L}\right)$. What assumption (A2) simply says is that the high quality is socially more beneficial than the low quality (which is trivially satisfied when the low quality is not socially beneficial). Finally, according to assumption (A3), the cost of the high quality is larger than the consumers' valuation of the low quality. ${ }^{11}$

\subsection{Full information benchmark}

We first analyze the full information case, in which consumers observe the investment and the realization of quality. We distinguish between two cases. In what is referred to below as case (1), low quality is socially beneficial $\left(r_{L} \geq\right.$ $c_{L}$ ) and is therefore put on the market under full information. Otherwise, if $r_{L}<c_{L}$, referred to as case (2), low quality is not socially beneficial and hence, not produced under full information.

Low quality is socially beneficial. When $r_{L} \geq c_{L}$, the firm's maximization problem is $\max _{\lambda} E \pi_{1}=\lambda\left(r_{H}-c_{H}\right)+(1-\lambda)\left(r_{L}-c_{L}\right)-(k / 2) \lambda^{2}$. Solving the first-order condition of profit maximization, we obtain as the probability for high-quality: $\left(r_{H}-c_{H}-r_{L}+c_{L}\right) / k$, which is positive under assumption (A2). Note that we have an interior solution if $k>r_{H}-c_{H}-r_{L}+c_{L}$ (otherwise the probability is 1$)$. We also check that the firm's expected profit evaluated at $\lambda=\left(r_{H}-c_{H}-r_{L}+c_{L}\right) / k$ is positive:

$$
\left.E \pi_{1}\right|_{\lambda=\left(r_{H}-c_{H}-r_{L}+c_{L}\right) / k}=\frac{1}{2 k}\left(r_{H}-c_{H}-r_{L}+c_{L}\right)^{2}+\left(r_{L}-c_{L}\right)>0
$$

In sum, the probability for high quality under full information in case (1) is

$$
\lambda_{1}^{f}= \begin{cases}\frac{1}{k}\left[\left(r_{H}-c_{H}\right)-\left(r_{L}-c_{L}\right)\right] & \text { if } k>r_{H}-c_{H}-r_{L}+c_{L} \equiv k_{0} \\ 1 & \text { if } k \leq k_{0} .\end{cases}
$$

Low quality is not socially beneficial. When it is assumed instead that $r_{L}<c_{L}$, the firm's problem is $\max _{\lambda} E \pi_{2}=\lambda\left(r_{H}-c_{H}\right)-(k / 2) \lambda^{2}$,

\footnotetext{
${ }^{11}$ Assumption (A3) is a technical assumption that allows us to rule out a case of little interest. The three assumptions are clearly compatible when the low quality is not socially beneficial $\left(r_{L}<c_{L}\right)$. Otherwise, assumptions (A2) and (A3) are compatible as long as $r_{L}<\left(r_{H}+c_{L}\right) / 2$.
} 
which yields the following profit-maximizing probability for high-quality: $\left(r_{H}-c_{H}\right) / k$, which is positive under assumption (A1). Note that we have an interior solution as long as $k>r_{H}-c_{H}$ (otherwise the probability is 1 ) and that the firm's expected profit evaluated at $\lambda=\left(r_{H}-c_{H}\right) / k$ is positive. We can then define the probability for high quality under full information in case (2) as

$$
\lambda_{2}^{f} \equiv \begin{cases}\frac{1}{k}\left(r_{H}-c_{H}\right) & \text { if } k>r_{H}-c_{H} \equiv k_{1}, \\ 1 & \text { if } k \leq k_{1} .\end{cases}
$$

\section{Asymmetric information}

In this section we analyze the situation of asymmetric information, in which consumers observe $I$ but not the realization of quality. We analyze perfect Bayesian equilibria of the game in which the firm observes quality after stage 1 and consumers only observe the investment level (and price) but not the realized quality. We treat separately the same two cases as in the full information benchmark: (1) $r_{L} \geq c_{L}$ and (2) $r_{L}<c_{L}$.

\subsection{Low quality is socially beneficial}

We start by considering the case with $r_{L} \geq c_{L}$. Suppose first that consumers expect any quality realization to be put on the market (clearly, if high quality is put on the market, so is low quality since its costs are lower). The expected surplus is thus $\lambda r_{H}+(1-\lambda) r_{L}$, which is the price the firm will set at stage 2. Hence, expected profits at stage 1 are

$$
\begin{aligned}
& \lambda\left[\lambda r_{H}+(1-\lambda) r_{L}-c_{H}\right]+(1-\lambda)\left[\lambda r_{H}+(1-\lambda) r_{L}-c_{L}\right]-(k / 2) \lambda^{2} \\
= & \lambda\left(r_{H}-c_{H}\right)+(1-\lambda)\left(r_{L}-c_{L}\right)-(k / 2) \lambda^{2} .
\end{aligned}
$$

Solving the first-order condition of profit maximization, we obtain as the probability for high-quality:

$$
\lambda^{a} \equiv \frac{1}{k}\left(r_{H}-c_{H}-r_{L}+c_{L}\right)
$$

We found the same value under full information. So, we already know that $\lambda^{a}<1$ provided that $k>k_{0}$ and, from expression (1), that the firm's expected profit evaluated at $\lambda=\lambda^{a}$ is positive when $r_{L} \geq c_{L}$. 
Comparing expression (4) with expression (2), we observe that, when consumers expect both qualities to be put on the market, the probability for high-quality is the same under asymmetric information and under full information $\left(\lambda^{a}=\lambda_{1}^{f}\right)$, meaning that investment incentives are not affected by consumer information if low quality is socially beneficial.

However, the previous conclusion only holds when a high quality product does actually stay in the market under asymmetric information. For this to be true, the firm must be interested in offering high quality. While it is always willing to do so under full information (under our assumption that $r_{H}>c_{H}$ ), it might prefer to stay out of the market under asymmetric information. In other words, the firm faces an adverse selection problem. For a high-quality firm to make positive operating profits, the price must exceed costs, i.e. $\lambda r_{H}+(1-\lambda) r_{L}-c_{H} \geq 0$, which is equivalent to

$$
\lambda \geq \widetilde{\lambda} \equiv \frac{c_{H}-r_{L}}{r_{H}-r_{L}}
$$

Hence, the firm will indeed implement $\lambda^{a}$ if $\lambda^{a} \geq \widetilde{\lambda}$, which can be rewritten as

$$
\lambda^{a} \geq \widetilde{\lambda} \Leftrightarrow k \leq \frac{r_{H}-r_{L}}{c_{H}-r_{L}}\left(r_{H}-c_{H}-r_{L}+c_{L}\right) \equiv k_{2},
$$

which is strictly positive (as well as $\tilde{\lambda}$ ) under assumption (A3). If $k>k_{2}$ and the firm implemented $\lambda^{a}$, consumers would know that a high-quality firm would not participate, so that their beliefs about product quality would not be confirmed. Consumers expect a sufficiently high probability that the product is of low-quality, which reduces their willingness to pay. Hence, the firm cannot charge a sufficiently high price to cover its cost in case it is of high quality. In such a case (i.e., $\lambda^{a}<\widetilde{\lambda}$ or $k>k_{2}$ ), the firm has the option to increase its investment expenditure, so as to increase the probability of high quality up to $\widetilde{\lambda}$.

In such a situation, overinvestment under asymmetric information is driven by, what we call, the adverse selection effect, as the overinvestment avoids adverse selection. The condition for this option to be profitable is the following. As $r_{L}>c_{L}$, the firm may alternatively invest zero and offer low quality on the market. The former action is more profitable than the latter if $\widetilde{\lambda}\left(r_{H}-c_{H}\right)+(1-\widetilde{\lambda})\left(r_{L}-c_{L}\right)-(k / 2) \widetilde{\lambda}^{2}>r_{L}-c_{L}$ or, equivalently, 
$\tilde{\lambda}\left[\left(r_{H}-c_{H}\right)-\left(r_{L}-c_{L}\right)\right]-(k / 2) \tilde{\lambda}^{2}>0$. Solving for $k$ we must have $k<$ $2\left[\left(r_{H}-c_{H}\right)-\left(r_{L}-c_{L}\right)\right] / \widetilde{\lambda}$, which is

$$
k<2 \frac{r_{H}-r_{L}}{c_{H}-r_{L}}\left[\left(r_{H}-c_{H}\right)-\left(r_{L}-c_{L}\right)\right]=2 k_{2} .
$$

As $k_{2}>k_{0}$ follows from assumption (A1), we now have a complete picture of the probability of high quality under asymmetric information in case (1). We compare it to the full information solution in the following lemma.

Lemma 1 When low quality is socially beneficial, the adverse selection effect drives the firm to overinvest in quality $\left(\lambda_{1}^{a}>\lambda_{1}^{f}\right)$ for intermediate values of the investment cost $\left(k_{2}<k \leq 2 k_{2}\right)$. For small values of the investment cost $\left(k_{2}<k \leq 2 k_{2}\right)$, investment incentives are not affected by consumer information $\left(\lambda_{1}^{a}=\min \left\{\lambda^{a}, 1\right\}=\lambda_{1}^{f}\right)$, while for large values of the investment cost $\left(k>2 k_{2}\right)$, the firm underinvests in quality $\left(\lambda_{1}^{a}=0<\lambda_{1}^{f}\right)$.

\subsection{Low quality is not socially beneficial}

We consider now the case with $r_{L}<c_{L}$ (meaning that under full information, low quality would not be put on the market). We start again by supposing that consumers expect any quality realization to be put on the market. As in the previous case, the probability for high-quality that maximizes the firm's expected profits at stage 1 is $\lambda^{a}$ for $k \leq k_{0}$, or 1 otherwise. The difference with the previous case is that the firm's expected profit evaluated at $\lambda=\lambda^{a}$ might now be negative as $r_{L}-c_{L}<0$. Therefore, in the present case, the firm is better off when it enters the market than when it is not active as long as $\lambda^{a}\left(r_{H}-c_{H}\right)+\left(1-\lambda^{a}\right)\left(r_{L}-c_{L}\right)-(k / 2)\left(\lambda^{a}\right)^{2}>0$, or

$$
k<\frac{\left(r_{H}-c_{H}-r_{L}+c_{L}\right)^{2}}{2\left(c_{L}-r_{L}\right)} \equiv k_{3} .
$$

It is easily checked that $r_{L}<c_{L}$ implies that $k_{1}<k_{0}<k_{3}$.

Comparing expression (4) with expression (3), we observe now that, when consumers expect both qualities to be put on the market, investment incentives are stronger under asymmetric information than under full information: $\lambda^{a}>\lambda_{2}^{f}$. Here, low-quality products are not released on the market under full information, but low quality is always consumed under asymmetric information. Since this expected lower quality is reflected in price 
and since low quality is produced at costs above the consumers' willingness to pay, the firm has an incentive to reduce the probability of low quality products through higher investments.

When low quality is not socially beneficial, there is thus an additional reason for firms to overinvest in quality. Overinvestment is driven by what we call the efficiency effect, as the firms attempt to make the probability of low quality realizations smaller under asymmetric information to avoid their inefficient release on the market. It is only when the investment cost is very high (i.e., $k>k_{3}$ ) that the firm prefers not to invest under asymmetric information while it keeps on investing under full information.

We still need to assess the adverse selection effect. We have indeed assumed so far that a high quality product stays in the market under asymmetric information. But what happens if the firm is not willing to offer high quality on the market? As we have shown above, a high-quality firm does not make positive operating profits when $\lambda<\widetilde{\lambda}$. Hence, consumers' beliefs about both qualities being offered are not confirmed if $\lambda^{a}<\tilde{\lambda}$ or $k>k_{2}$. As in the previous case, the adverse selection effect might then drive the firm to overinvest in quality (i.e., to choose $\widetilde{\lambda}$ instead of $\lambda^{a}$ ). What changes in the present case is the condition for this overinvestment to be profitable. Here, the alternative for the firm is to invest zero and stay altogether out of the market (whereas, in case (1), the firm could still produce the socially beneficial low quality). Hence, with $r_{L}<c_{L}$, overinvestment is profitable if $\tilde{\lambda}\left(r_{H}-c_{H}\right)+(1-\tilde{\lambda})\left(r_{L}-c_{L}\right)-(k / 2) \tilde{\lambda}^{2}>0$, which is equivalent to

$$
k<\frac{2\left(r_{H}-r_{L}\right)\left(c_{H}-c_{L}\right)\left(r_{H}-c_{H}\right)}{\left(c_{H}-r_{L}\right)^{2}} \equiv k_{4} .
$$

Hence, overinvestment to avoid adverse selection occurs as long as $k$ is comprised between $k_{2}$ and $k_{4}$. This is only possible if $k_{4}>k_{2}$, or equivalently if

$$
c_{L}<r_{L}+\Delta \text {, with } \Delta \equiv \frac{\left(c_{H}-r_{L}\right)\left(r_{H}-c_{H}\right)}{\left(2 r_{H}-r_{L}-c_{H}\right)}>0,
$$

i.e., if the cost of the low quality is not too large (though it is larger, in case (2), than the valuation of the low quality).

We thus need to distinguish between two sub-cases. In case $(2 \mathrm{a}), c_{L}<$ $r_{L}+\Delta$ and there exist values of the investment cost for which the adverse 
selection effect leads the firm to overinvest $\left(k_{2}<k<k_{4}\right)$. Moreover, a few lines of computation establish that

$$
k_{3}-k_{4}=\frac{\left(r_{L} r_{H}-2 c_{L} r_{H}-r_{L}^{2}+r_{L} c_{L}+r_{H} c_{H}-c_{H}^{2}+c_{L} c_{H}\right)^{2}}{2\left(c_{L}-r_{L}\right)\left(c_{H}-r_{L}\right)^{2}}>0 .
$$

We can therefore summarize the situation in case $(2 \mathrm{~b})$ as in the following table (where $\lambda_{2}^{a}$ denotes the probability of high quality under asymmetric information in case (2)).

\begin{tabular}{|l|l|l|}
\hline$k \leq k_{1}$ & $\lambda_{2}^{a}=\lambda_{2}^{f}=1$ & no effect of information \\
\hline$k_{1}<k \leq k_{2}$ & $\lambda_{2}^{a}=\min \left\{\lambda^{a}, 1\right\}>\lambda_{2}^{f}$ & overinvestment (efficiency) \\
\hline$k_{2}<k \leq k_{4}$ & $\lambda_{2}^{a}=\widetilde{\lambda}>\lambda_{2}^{f}$ & $\begin{array}{l}\text { overinvestment (efficiency } \\
+ \text { adverse selection) }\end{array}$ \\
\hline$k>k_{4}$ & $\lambda_{2}^{a}=0<\lambda_{2}^{f}$ & underinvestment \\
\hline
\end{tabular}

In contrast, in case $(2 \mathrm{~b}), c_{L} \geq r_{L}+\Delta$ and the firm never overinvests in quality to avoid the adverse selection effect (as $k_{4} \leq k_{2}$ ). Then, the comparison between the asymmetric and the full information solutions is as follows.

\begin{tabular}{|l|l|l|}
\hline$k \leq k_{1}$ & $\lambda_{2}^{a}=\lambda_{2}^{f}=1$ & no effect of information \\
\hline$k_{1}<k \leq k_{3}$ & $\lambda_{2}^{a}=\min \left\{\lambda^{a}, 1\right\}>\lambda_{2}^{f}$ & overinvestment (efficiency) \\
\hline$k>k_{3}$ & $\lambda_{2}^{a}=0<\lambda_{2}^{f}$ & underinvestment \\
\hline
\end{tabular}

We collect the results about the two sub-cases in the next lemma.

Lemma 2 When low quality is not socially beneficial, overinvestment may occur because of the efficiency effect only (if $c_{L} \geq r_{L}+\Delta$ and $k_{1}<k \leq k_{3}$, or if $c_{L}<r_{L}+\Delta$ and $k_{1}<k \leq k_{2}$ ) or because of a combination of the efficiency and the adverse selection effects (if $c_{L}<r_{L}+\Delta$ and $k_{2}<k \leq k_{4}$ ). Otherwise, for low values of the investment cost, investment incentives are not affected by consumer information $\left(\lambda_{2}^{a}=\lambda_{2}^{f}\right)$, while for large values of the investment cost, the firm underinvests in quality $\left(\lambda_{2}^{a}=0<\lambda_{2}^{f}\right)$.

\subsection{Summary and illustration}

Proposition 1 collects the results of Lemmata 1 and 2. 
Proposition 1 If consumers observe investments in the quality of products but not the quality itself, a firm invests strictly more in quality under asymmetric information than under full information, provided that (1) $r_{L} \geq c_{L}$ and $k_{2}<k \leq 2 k_{2}$ or (2a) $r_{L}<c_{L}<r_{L}+\Delta$ and $k_{1}<k \leq k_{4}$, or (2b) $r_{L}+\Delta \leq c_{L}$ and $k_{1}<k \leq k_{3}$. In case (1) overinvestment is due to the adverse selection effect; in case (2a), it is due to the efficiency effect or to a combination of the two effects; in case (2b), it is due to the efficiency effect only.

The three situations of over-investment are depicted in Figure 1. To get the intuition behind our result, let us restate the argument. First, we have seen that ignoring the participation constraint of the high-quality firm, investment incentives weakly increase under asymmetric information compared to full information. The reason for the potential overinvestment is that a low-quality firm stays in the market under asymmetric information even though its value is less than the cost because it is sold at the expected and not the actual value. The fact that the product may be of low quality is taken into account by consumers and thus reflected in the price. Therefore, by investing more, the firm can convince consumers that the risk of obtaining low quality is reduced. This is the efficiency effect.

Secondly, taking into account the participation constraint of a highquality firm, investments under given beliefs may be insufficient to make selling high quality worthwhile. This implies that $\lambda^{a}$ cannot be the equilibrium belief at the investment level $I\left(\lambda^{a}\right)$. To make the participation of the high-quality firm worthwhile, the firm has to distort its investment upward in order to convince consumers that a high-quality outcome is more likely, in which case they are willing to pay more. Thirdly, at the investment stage the firm has to compare profits with such an upward distorted investment to the outside option (which is either zero or to sell low quality). It may be profitable to overinvest. This is the adverse selection effect.

Finally, it is only when investments are too costly (i.e. $k>2 k_{2}$ for $r_{L}>c_{L}$ or $k>k_{3}$ or $k_{4}$ for $r_{L}<c_{L}$ ) that the standard underinvestment result under asymmetric information holds. 


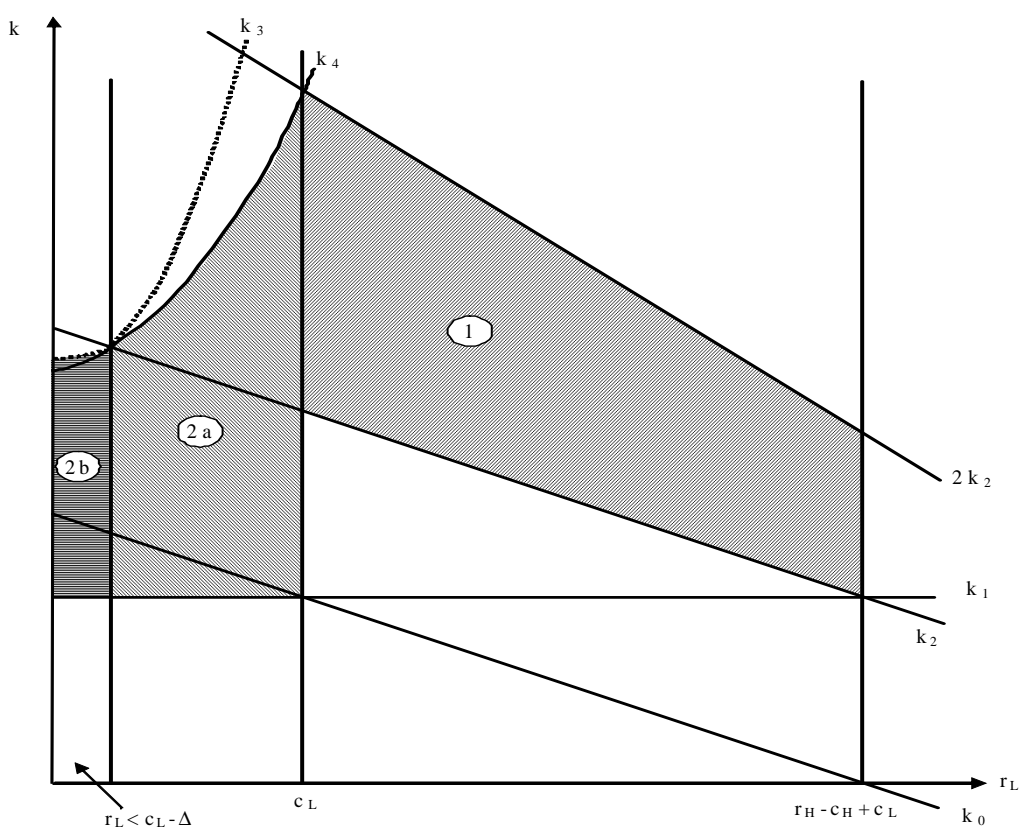

Figure 1: Overinvestment under asymmetric information

A numerical example (which gives parameter values to all parameters except $k$ ) illustrates our results for cases (1) and (2a). Take $r_{H}=10$, $c_{H}=6$, and $c_{L}=2$. We take two values for $r_{L}$ : either $r_{L}=3>c_{L}$ (case (1)) or $r_{L}=1<c_{L}$ (case (2a)). Consider first case (1) with $r_{L}=3$. Under full information, the firm would choose its investment such that $\lambda_{1}^{f}=3 / k$. As we have seen above, under asymmetric information and provided that consumers expect that products are sold on the market independent of the realization of the random variable, the firm would invest such that $\lambda^{a}=\lambda_{1}^{f}$. However, for a high-quality firm to make positive operating profits the price must exceed costs, i.e. $\lambda r_{H}+(1-\lambda) r_{L}-c_{H} \geq 0$, which becomes $\lambda \geq \widetilde{\lambda} \equiv 3 / 7$ under our parameter values. Hence, the firm will indeed implement $\lambda^{a}$ if $\lambda^{a} \geq \tilde{\lambda}$. Otherwise, if the firm implemented $\lambda^{a}$, consumers' beliefs about product quality would not be confirmed. The firm can then increase its investment expenditure to increase the probability of high quality. Expected quality is higher than under full information if $\widetilde{\lambda}=3 / 7>3 / k=\lambda_{1}^{f}$, which is equivalent to $k>k_{2}=7$. To be an equilibrium strategy also at the investment stage, expected profits must be greater than $r_{L}-c_{L}=1$, i.e. 
$4 \lambda+(1-\lambda)-(k / 2) \lambda^{2} \geq 1$. Evaluated at $\widetilde{\lambda}=3 / 7$, this is equivalent to $k \leq 2 k_{2}=14$. Hence, for parameter values $k \in(7,14]$ the firm invests strictly more under asymmetric than under full information.

Suppose now that $r_{L}=1$, so that we are in case (2a). We check that $c_{L}-r_{L}=1<\Delta=20 / 13$, so that $k_{3}>k_{2}$. Under full information, the firm would choose its investment such that $\lambda_{2}^{f}=4 / k$. Hence, $k_{1}=4$. Redoing the computations under asymmetric information, we find that $k_{0}=5, k_{2}=9$, $k_{4} \simeq 11.5$ and $k_{3}=12.5$. Take, e.g., $k=10$ and compute the various thresholds on $\lambda:^{12}$

$$
\widetilde{\lambda}=\frac{5}{9}>\lambda^{a}=\frac{1}{2}>\lambda_{2}^{f}=\frac{2}{5} .
$$

Hence, for parameter values $k \in(4,11.5]$ the firm invests strictly more under asymmetric information than under full information. For an intermediate range of investment cost levels $(k \in(9,11.5))$ the firm has to further increase its investment in order to convince consumers that a high-quality product will be put on the market. Only if investment costs are too high $(k>11.5)$, investment under asymmetric information breaks down to zero and is therefore less than under full information. Figure 2 illustrates our results in case $(2 \mathrm{a})$, where $r_{L}<c_{L} \cdot{ }^{13}$

In the exposition above we chose a quadratic investment cost function merely to provide a simple explicit characterization. Focussing on the adverse selection effect, we show that the overinvestment result may obtain for any strictly convex investment cost function $I(\lambda)$ with $I^{\prime}(\lambda)>0, I^{\prime \prime}(\lambda)>0$, $I^{\prime}(0)=0$, Here, to obtain interior solutions, we impose the boundary conditions $\lim _{\lambda \rightarrow 1} I^{\prime}(\lambda)=\infty$.

Under full information, and assuming that the low quality is socially beneficial, we obtain

$$
\lambda^{f}=I^{\prime^{-1}}\left[\left(r_{H}-c_{H}\right)-\left(r_{L}-c_{L}\right)\right] .
$$

\footnotetext{
${ }^{12}$ We have checked that expected profits at stage 1 under $\widetilde{\lambda}$ are positive (namely, $\widetilde{\lambda}\left(r_{H}-\right.$ $\left.\left.c_{H}\right)+(1-\tilde{\lambda})\left(r_{L}-c_{L}\right)-(k / 2) \widetilde{\lambda}^{2}=19 / 81\right)$.

${ }^{13}$ Although the firm invests more under asymmetric information, it can easily be checked that it always makes at least as much profits under full information than under asymmetric information.
} 


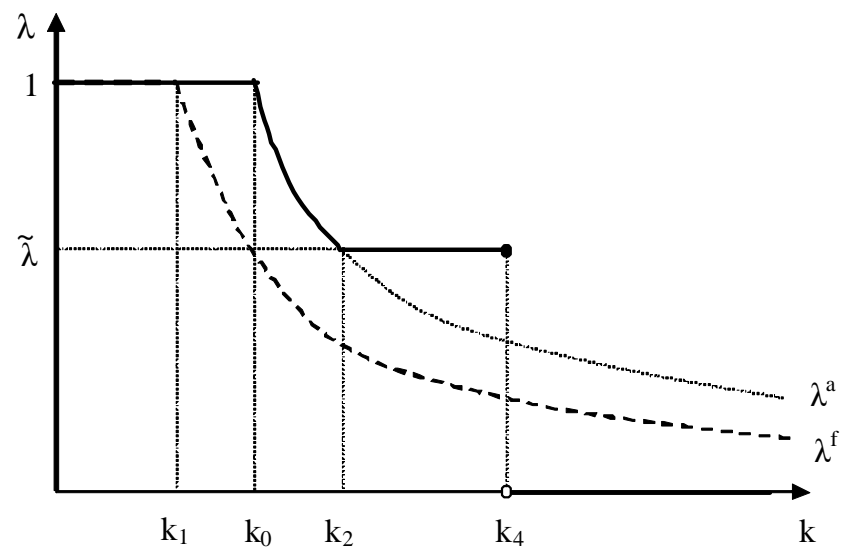

Figure 2: Investment in quality in case (2a)

Under asymmetric information, a firm ignoring the participation constraint would choose the same level of investment that is implied by $\lambda^{f}$, i.e., $\lambda^{a}=I^{\prime^{-1}}\left[\left(r_{H}-c_{H}\right)-\left(r_{L}-c_{L}\right)\right]$. Now, taking the participation constraint into account, $\lambda^{a}$ is the firm's actual choice as long as the price exceeds costs, i.e. $\lambda r_{H}+(1-\lambda) r_{L}-c_{H} \geq 0$, which is equivalent to $\lambda \geq \tilde{\lambda}=\left(c_{H}-r_{L}\right) /\left(r_{H}-r_{L}\right)$. Hence, the firm will indeed implement $\lambda^{a}$ if $\lambda^{a} \geq \tilde{\lambda}$, or

$$
I^{\prime^{-1}}\left[\left(r_{H}-c_{H}\right)-\left(r_{L}-c_{L}\right)\right] \geq \frac{c_{H}-r_{L}}{r_{H}-r_{L}} .
$$

Otherwise, the firm may find it profitable to increase its investment up to $I(\widetilde{\lambda})$. This is so if $\tilde{\lambda}\left(r_{H}-c_{H}\right)+(1-\tilde{\lambda})\left(r_{L}-c_{L}\right)-I(\widetilde{\lambda})>r_{L}-c_{L}$ or, equivalently, $\tilde{\lambda}\left[\left(r_{H}-c_{H}\right)-\left(r_{L}-c_{L}\right)\right]-I(\widetilde{\lambda})>0$. Define the average investment cost $J(\lambda) \equiv I(\lambda) / \lambda$. We must have $\left[\left(r_{H}-c_{H}\right)-\left(r_{L}-c_{L}\right)\right]-J(\widetilde{\tilde{\lambda}})>$ 0 . Denote $\widetilde{\widetilde{\lambda}}$ as the solution to $\left[\left(r_{H}-c_{H}\right)-\left(r_{L}-c_{L}\right)\right]-J(\lambda)=0$, i.e. $\widetilde{\widetilde{\lambda}}=$ $J^{-1}\left[\left(r_{H}-c_{H}\right)-\left(r_{L}-c_{L}\right)\right]$. If $\tilde{\lambda}<\widetilde{\widetilde{\lambda}}$, overinvestment in order to avoid adverse selection is profitable. To summarize, we must have

$$
I^{\prime^{-1}}\left[\left(r_{H}-c_{H}\right)-\left(r_{L}-c_{L}\right)\right]<\frac{c_{H}-r_{L}}{r_{H}-r_{L}}<J^{-1}\left[\left(r_{H}-c_{H}\right)-\left(r_{L}-c_{L}\right)\right] .
$$

Fix $D \equiv\left(r_{H}-c_{H}\right)-\left(r_{L}-c_{L}\right)$. By the strict convexity of $I$, we have that $I^{\prime^{-1}}(D)<J^{-1}(D)$. Hence, if the parameters are such that the ratio $\left(c_{H}-r_{L}\right) /\left(r_{H}-r_{L}\right)$ lies in some appropriately defined intermediate range, then overinvestment occurs because of the adverse selection effect. 


\section{Extensions}

In this section, we test the robustness of our results by extending the previous analysis into several directions. ${ }^{14}$ We first introduce outside options in order to solve the moral hazard problem. We show that the adverse selection and the efficiency effects are still at play under this alternative setting. Second, we assume that the seller can only partially extract the rent. Third, we assume that consumers have heterogeneous valuations for quality. In the latter two extensions, we focus on the adverse selection effect and we show that there exist situations where this effect drives the firm to invest more in quality under asymmetric than under full information.

\subsection{The analysis with outside options}

Our analysis can be criticized for the fact that under asymmetric information, high quality is less profitable than low quality since both are sold at the same price, while low quality is cheaper to produce. If a successful investment enables the firm not only to produce high but also low quality, the firm will always deviate to low quality due to the moral hazard problem. This in turn would imply that a firm does not have any incentive to invest under high quality because a higher investment does not contain information about the expected product quality that will be put on the market. However, if the production cost of high and low quality is the same whereas high and low quality give different values for an outside option, a high quality firm does not have an incentive to deviate to low quality (provided that its production costs do not increase in quality). ${ }^{15}$ We show that our qualitative

\footnotetext{
${ }^{14}$ To keep the exposition simple, we use (and sometimes slightly abuse) the notation we introduced in the previous section.

${ }^{15}$ For an analysis of quality increasing outside options in a signaling context, see Daughety and Reinganum (2005). We can also think of the outside option as a costly action taken by the firm; in particular, it may use the services of a third-party certifyer, who certifies realized product quality (for an analysis of fully revealing third-party certification, see Biglaiser, 1993; for the use of third-party certification as an alternative option within a price signaling context, see Daughety and Reinganum, 2007). If this action fully reveals its product quality, the firm can sell high quality under full information at a price $r_{H}$. For instance, if $t$ is the cost of certification then $v_{H}=r_{H}-t$ and $v_{L}=r_{L}-t$ are the values of the outside option.
} 
findings from above are confirmed.

Let $v_{H}$ and $v_{L}$ denote the value of the outside option for high and low quality, respectively, while $c$ denotes the production cost which is independent of quality. By the nature of the problem, $r_{H}>v_{H}>r_{L}>v_{L}$. In addition, we assume that the value of the outside option for high quality exceeds production costs, $v_{H}>c$. We can then replicate the analysis of Section 2.2. First, we obtain the probability for high quality under full information as

$$
\lambda^{f} \equiv \begin{cases}\frac{1}{k}\left(r_{H}-c\right) & \text { if } r_{L}<c \\ \frac{1}{k}\left(r_{H}-r_{L}\right) & \text { if } r_{L} \geq c\end{cases}
$$

and we define $\hat{k}_{0} \equiv r_{H}-c$. Next, we turn to the analysis under asymmetric information and consider first the case $r_{L} \geq c$. In analogy to Section 3, we obtain that $\hat{\lambda}^{a}=(1 / k)\left(r_{H}-r_{L}\right)$ and $\widehat{\tilde{\lambda}}=\left(v_{H}-r_{L}\right) /\left(r_{H}-r_{L}\right)$, where the latter expression comes from the condition that the price $\lambda r_{H}+(1-\lambda) r_{L}$ has to exceed the value of the outside option for a high-quality product $v_{H}$. We then can calculate the critical value of $k$ above which overinvestment with $\widehat{\tilde{\lambda}}>\hat{\lambda}^{a}$ may be required to solve the adverse selection problem:

$$
\hat{k}_{2}=\frac{\left(r_{H}-r_{L}\right)^{2}}{v_{H}-r_{L}} .
$$

For an investment $I(\lambda)$ with $\lambda \leq \hat{\lambda}^{a}$ to be worthwhile, we must have that the profit is non-negative for $r_{L}<c$. We obtain that this is the case for all $k \leq \hat{k}_{3}$ where

$$
\hat{k}_{3}=\frac{\left(r_{H}-r_{L}\right)^{2}}{2\left(c-r_{L}\right)},
$$

which is always greater than $\hat{k}_{0}$. Hence, the non-negativity condition is not binding for all $k \leq \hat{k}_{2}$ if $\hat{k}_{3}>\hat{k}_{2}$. This is equivalent to $v_{H}+r_{L}>2 c$.

Consider now $k>k_{2}$. For $r_{L}>c$, an upward distortion of the investment gives greater profit than offering low quality in the market at zero investment, i.e. $\lambda r_{H}+(1-\lambda) r_{L}-c-(k / 2) \lambda^{2}>r_{L}-c$, as long as $k<2 \hat{k}_{2}$. Overinvestment results then from the adverse selection effect.

For $r_{L} \leq c$, an upward distortion of the investment gives greater profit than being inactive with zero investment, i.e. $\lambda r_{H}+(1-\lambda) r_{L}-c-(k / 2) \lambda^{2}>$ 
0 , as long as $k<\hat{k}_{4}$ where $^{16}$

$$
\hat{k}_{4}=2 \frac{v_{H}-c}{v_{H}-r_{L}} \frac{\left(r_{H}-r_{L}\right)^{2}}{v_{H}-r_{L}} .
$$

Here, it is a combination of the efficiency and the adverse selection effects that drives the overinvestment.

We can summarize our analysis as follows.

Proposition 2 Suppose that a successful investment allows the firm to choose between high and low quality, which are produced at equal cost, but that high quality has a higher value than an outside option. If consumers observe investments in the quality of products but not quality itself, a firm invests strictly more in quality under asymmetric information than under full information, provided that (1) $r_{L}>c$ and $\hat{k}_{2}<k \leq \hat{k}_{4}$, or (2) $r_{L}<c$ and $\hat{k}_{0}<k \leq \max \left\{\hat{k}_{2}, \hat{k}_{3}\right\}$. In case (1) overinvestment is due to the adverse selection effect; in case (2), it is due to the to a combination of the efficiency and the adverse selection effects.

\subsection{Partial surplus extraction}

In this extension, we depart from the initial framework by assuming that the firm can only extract a share $\alpha$ (with $0<\alpha<1$ ) of the surplus. We focus here on the case where the low quality is socially beneficial $\left(r_{L} \geq c_{L}\right)$; hence, if overinvestment occurs, it can only be due to the adverse selection effect.

We start with the full information benchmark. The firm's maximization problem in stage 1 is $\max _{\lambda} E \pi=\lambda \alpha\left(r_{H}-c_{H}\right)+(1-\lambda) \alpha\left(r_{L}-c_{L}\right)-(k / 2) \lambda^{2}$. Solving the first-order condition of profit maximization, we obtain as the probability for high-quality: $\alpha\left(r_{H}-c_{H}-r_{L}+c_{L}\right) / k$. For low values of $k$, this probability is larger than one. Hence, the probability for high quality under full information is

$\lambda^{f}(\alpha)= \begin{cases}\frac{\alpha}{k}\left[\left(r_{H}-c_{H}\right)-\left(r_{L}-c_{L}\right)\right] & \text { if } k>\alpha\left[r_{H}-c_{H}-r_{L}+c_{L}\right] \equiv k_{0}(\alpha), \\ 1 & \text { if } k \leq k_{0}(\alpha) .\end{cases}$

\footnotetext{
${ }^{16}$ The inequality can be rewritten as $2\left[\lambda\left(r_{H}-r_{L}\right)+r_{L}-c\right] / \lambda^{2}>k$. To obtain $\hat{k}_{4}$, we substitute the expression for $\hat{\tilde{\lambda}}$. Clearly, $\hat{k}_{4}>\hat{k}_{3}$ is equivalent to $\left(v_{H}+r_{L}\right) / 2>c$ because in this case profits at $\hat{\lambda}^{a}$ are strictly positive, so that an upward distortion that solves the adverse selection problem is worthwhile.
} 
Consider now the asymmetric information case. Suppose first that consumers expect any quality realization to be put on the market. Buyers pay the price that implements the surplus sharing rule $\alpha$. Hence, they pay their expected willingness to pay $\lambda r_{H}+(1-\lambda) r_{L}$ minus their share $(1-\alpha)$ of the total surplus $\lambda\left(r_{H}-c_{H}\right)+(1-\lambda)\left(r_{L}-c_{L}\right)$. That is, the payment is given by

$$
\begin{aligned}
& \lambda r_{H}+(1-\lambda) r_{L}-(1-\alpha)\left[\lambda\left(r_{H}-c_{H}\right)+(1-\lambda)\left(r_{L}-c_{L}\right)\right] \\
= & \alpha\left[\lambda r_{H}+(1-\lambda) r_{L}\right]+(1-\alpha)\left[\lambda c_{H}+(1-\lambda) c_{L}\right] .
\end{aligned}
$$

The expected seller surplus is thus $\alpha\left[\lambda\left(r_{H}-c_{H}\right)+(1-\lambda)\left(r_{L}-c_{L}\right)\right]$. Hence, expected profits at stage 1 are

$$
\alpha\left[\lambda\left(r_{H}-c_{H}\right)+(1-\lambda)\left(r_{L}-c_{L}\right)\right]-(k / 2) \lambda^{2} .
$$

Solving the first-order condition of profit maximization, we obtain as the probability for high-quality:

$$
\lambda^{a}(\alpha) \equiv \frac{\alpha}{k}\left[\left(r_{H}-c_{H}\right)-\left(r_{L}-c_{L}\right)\right] .
$$

We know from our previous analysis that $\lambda^{a}(\alpha)$ is the actual firm's choice as long as it allows the firm to make positive operating profits. That is, the payment must exceed costs $c_{H}$, i.e., $\alpha\left[\lambda r_{H}+(1-\lambda) r_{L}\right]+(1-\alpha)\left[\lambda c_{H}+(1-\right.$ $\left.\lambda) c_{L}\right]-c_{H} \geq 0$, which is equivalent to

$$
\lambda \geq \widetilde{\lambda}(\alpha) \equiv \frac{c_{H}-\alpha r_{L}-(1-\alpha) c_{L}}{\alpha\left(r_{H}-r_{L}\right)+(1-\alpha)\left(c_{H}-c_{L}\right)} .
$$

Therefore, the firm will indeed implement $\lambda^{a}$ if $\lambda^{a}(\alpha) \geq \widetilde{\lambda}(\alpha)$, which can be rewritten as

$$
k \leq \frac{\alpha\left(r_{H}-r_{L}\right)+(1-\alpha)\left(c_{H}-c_{L}\right)}{c_{H}-\alpha r_{L}-(1-\alpha) c_{L}} \alpha\left(r_{H}-c_{H}-r_{L}+c_{L}\right) \equiv k_{2}(\alpha) .
$$

If $k>k_{2}(\alpha)$, then the firm has the option to increase its investment expenditure, so as to increase the probability of high quality up to $\widetilde{\lambda}(\alpha)$. This option must yield larger profits than investing zero and offering only the low quality. That is, $\alpha\left[\widetilde{\lambda}(\alpha)\left(r_{H}-c_{H}\right)+(1-\tilde{\lambda}(\alpha))\left(r_{L}-c_{L}\right)\right]-(k / 2) \widetilde{\lambda}(\alpha)^{2}>\alpha\left(r_{L}-c_{L}\right)$ 
or, equivalently, $\alpha \widetilde{\lambda}(\alpha)\left[\left(r_{H}-c_{H}\right)-\left(r_{L}-c_{L}\right)\right]-(k / 2) \widetilde{\lambda}(\alpha)^{2}>0$. Solving for $k$ we must have $k<2 \alpha\left[\left(r_{H}-c_{H}\right)-\left(r_{L}-c_{L}\right)\right] / \widetilde{\lambda}(\alpha)$, which is

$$
k<2 \frac{\alpha\left(r_{H}-r_{L}\right)+(1-\alpha)\left(c_{H}-c_{L}\right)}{c_{H}-\alpha r_{L}-(1-\alpha) c_{L}} \alpha\left(r_{H}-c_{H}-r_{L}+c_{L}\right)=2 k_{2}(\alpha) .
$$

We finally check that $r_{H}>c_{H}$ implies that $k_{2}(\alpha)>k_{0}(\alpha)$. We therefore observe that the results we obtained in the previous section with full rent extraction carry over to the case of partial rent extraction. Indeed, overinvestment is observed for $k_{2}(\alpha)<k \leq 2 k_{2}(\alpha)$ : for such values of the investment cost, the firm chooses $\widetilde{\lambda}(\alpha)$, which is above the full information level.

The only noteworthy difference to our previous analysis is that the investment under full information is insufficient from a social point of view because the seller can only appropriate part of the surplus. Thus, the presence of asymmetric information may alleviate the social underinvestment problem. Indeed, the expected total net surplus is given by $S(\lambda)=$ $\lambda\left(r_{H}-c_{H}\right)+(1-\lambda)\left(r_{L}-c_{L}\right)-(k / 2) \lambda^{2}$. We know from our previous analysis that $S(\lambda)$ reaches a maximum at $\lambda=(1 / k)\left[\left(r_{H}-c_{H}\right)-\left(r_{L}-c_{L}\right)\right]$, which is equal to what we refer to as $\lambda^{f}(1)$ in the present subsection. We have also computed above that $\widetilde{\lambda}(\alpha)<\lambda^{f}(1)$ for $k<k_{2}$ (1). Therefore, for $k_{2}(\alpha)<k \leq \min \left\{2 k_{2}(\alpha), k_{2}(1)\right\}$, the firm invests more under asymmetric information than under full information, and this overinvestment expands the expected total net surplus (as $k<k_{2}$ (1) implies that we are in the increasing section of $S(\lambda)) \cdot{ }^{17}$

\subsection{Heterogeneous consumers}

We suppose now that consumers share the same valuation $r_{L}=0$ but differ in their valuation for high quality $r_{H}$. The cumulative distribution function over $r_{H}$ is denoted by $F: \mathbb{R}_{+} \rightarrow[0,1]$. We assume that $F$ is continuous on $\mathbb{R}_{+}$and has a density $f$ that takes values $f(r)>0$ and is continuously

\footnotetext{
${ }^{17}$ It is easily seen that $2 k_{2}(\alpha)<k_{2}(1)$ is equivalent to $\alpha<1 / 2$. Hence, if the firm appropriates less than half of the surplus, then the overinvestment due to the adverse selection effect is always welfare improving. On the other hand, if $\alpha>1 / 2$ and $k_{2}(1)<$ $k<2 k_{2}(\alpha)$, then we are in the decreasing section of $S(\lambda)$ and welfare is improved as long as $S(\tilde{\lambda}(\alpha))>S\left(\lambda^{f}(\alpha)\right)$.
} 
differentiable for all $r \in(\underline{r}, \bar{r})$, where $\bar{r} \in \mathbb{R}_{+} \cup\{\infty\}$, and $f(r)=0$ for all $r \notin[\underline{r}, \bar{r}]$. Note that we allow for $f(\underline{r})$ and $f(\bar{r})$ to be zero or strictly positive. We assume that the inverse hazard rate $h(\cdot) \equiv(1-F(\cdot)) / f(\cdot)$ is nonincreasing in $r$ and $h(\bar{r})=0$ if $\bar{r}$ is finite. The monotone hazard rate assumption is satisfied if and only if $1-F$ is log-concave; this property holds for a variety of parametric distribution functions (see e.g. Bagnoli and Bergstrom, 2005). To focus on the adverse selection effect, we set $c_{L}=0$.

In contrast with our initial framework, we assume here that the firm is able to commit to its price at the investment stage. ${ }^{18}$ The timing of the game is thus now as follows: in stage 1, the firm chooses $\lambda$ and $p$, and in stage 2 , consumers learn $\lambda$ and $p$, form beliefs about product quality according to $\lambda$, and make their purchasing decision.

Under symmetric information, the firm solves $\max _{p, \lambda} \pi^{f}(p, \lambda)-I(\lambda)$ where $\pi^{f}=\lambda[1-F(p)]\left(p-c_{H}\right)$, and $I(\lambda)$ is such that $I^{\prime}>0, I^{\prime \prime}>0$, $I^{\prime}(0)=0$ and $\lim _{\lambda \rightarrow 1} I^{\prime}(\lambda)=\infty$. Consider first the pricing decision. Note that the profit-maximizing price is independent of the investment decision. The first-order condition with respect to $p$ is

$$
[1-F(p)]-f(p)\left(p-c_{H}\right)=0 \Leftrightarrow p=c_{H}+h(p) .
$$

By the monotone hazard rate assumption, the right-hand side is nonincreasing. Furthermore, the right-hand side evaluated at $c_{H}$ is strictly greater than $c_{H}$. In addition, evaluated in the limit as $p \rightarrow \bar{r}$, it is strictly less than $\bar{r}$ because it turns to $c_{H}$ for $p^{f} \rightarrow \bar{r}$ if $\bar{r}$ is finite and it is bounded from above by some finite number if $\bar{r}$ is infinite. Hence, $p^{f}$ is uniquely determined by the solution to (5). The first-order condition with respect to $\lambda$ is simply found as $[1-F(p)]\left(p-c_{H}\right)=I^{\prime}(\lambda)$. Since the left-hand side is constant in

\footnotetext{
${ }^{18}$ Price commitment in our context means that product features and price are determined and advertised before actual quality is realized. Instead of price commitment, we may equivalently assume that the firm makes a capacity commitment before actual quality is realized and that consumers bid for the products. The adverse selection effect comes into play very naturally in this context. Indeed, it is the expected marginal cost that is relevant for the price (or capacity) decision. Hence, ignoring adverse selection, the profitmaximizing price may be less than $c_{H}$. In contrast, without price commitment, the firm would optimally set its price above $c_{H}$ if $\lambda \bar{r}>c_{H}$. Hence, only for finite $\bar{r}$ and sufficiently steep investment costs would the adverse selection effect come into play.
} 
$\lambda$ and the right-hand side increasing with $I^{\prime}(0)=0$ and $\lim _{\lambda \rightarrow 1} I^{\prime}(\lambda)=\infty$, there exists a unique solution $\lambda^{f}$ to this problem:

$$
\begin{aligned}
\lambda^{f} & =I^{\prime^{-1}}\left(\left[1-F\left(p^{f}\right)\right]\left(p^{f}-c_{H}\right)\right) \\
& =I^{\prime^{-1}}\left(f\left(p^{f}\right) h\left(p^{f}\right)^{2}\right),
\end{aligned}
$$

where the second line uses expression (5) and the fact that $[1-F(\cdot)]=$ $f(\cdot) h(\cdot)$.

At stage 2, under asymmetric information, a consumer of type $r_{H}$ observes $\lambda$ and $p$, and buys the product if $\lambda r_{H}-p \geq 0$. Hence, all consumers with $r_{H} \geq p / \lambda$ buy, so that expected demand for the product is $1-F(p / \lambda)$. Therefore, at stage 1 , ignoring the firm's participation constraint at stage 2 , the firm solves

$$
\max _{p, \lambda}[1-F(p / \lambda)]\left(p-\lambda c_{H}\right)-I(\lambda)
$$

The first-order condition with respect to $p$ is

$$
[1-F(p / \lambda)]-\frac{1}{\lambda} f(p / \lambda)\left(p-\lambda c_{H}\right)=0 \Leftrightarrow p^{a}=\lambda c_{H}+\lambda h\left(p^{a} / \lambda\right) .
$$

Using the same arguments as for $p^{f}$, we know that $p^{a}$ is uniquely determined by the solution to (7). It is also easily seen that $p^{a}$ increases with $\lambda$. The first-order condition with respect to $\lambda$ is

$$
\begin{aligned}
\frac{p}{\lambda^{2}} f(p / \lambda)\left(p-\lambda c_{H}\right)-c_{H}[1-F(p / \lambda)] & =I^{\prime}(\lambda) \Leftrightarrow \\
f(p / \lambda)\left(\frac{p}{\lambda^{2}}\left(p-\lambda c_{H}\right)-c_{H} h(p / \lambda)\right) & =I^{\prime}(\lambda) .
\end{aligned}
$$

Replacing $p$ by its optimal value $p^{a}$ in the latter expression and using expression (7), we obtain ${ }^{19}$

$$
\lambda^{a}=I^{\prime^{-1}}\left(f\left(p^{a} / \lambda^{a}\right) h\left(p^{a} / \lambda^{a}\right)^{2}\right) .
$$

As we have seen above, three conditions must be fulfilled for the adverse selection effect to entail overinvestment in quality. First, the participation constraint must be binding. This is so if $p^{a}<c_{H}$ holds, which is equivalent (as $p^{a}$ is an increasing function of $\lambda$ ) to $\lambda^{a}$ being below some threshold $\tilde{\lambda}$.

\footnotetext{
${ }^{19}$ We have checked that the second-order conditions for a maximum in $p$ and $\lambda$ are satisfied.
} 
The alternative strategy for the firm is then to invest $I(\tilde{\lambda})$ instead of $I\left(\lambda^{a}\right)$, and concomitantly, to set $p=c_{H}$ instead of $p=p^{a}$. The expected profit is then equal to $\left[1-F\left(c_{H} / \tilde{\lambda}\right)\right](1-\tilde{\lambda}) c_{H}-I(\tilde{\lambda})$ and the second condition is that this profit be positive. Finally, if the two first conditions are met, we can talk of overinvestment with respect to the full information case if $\tilde{\lambda}>\lambda^{f}$.

We now take a specific example to illustrate that our overinvestment result is preserved in this generalized setting. Suppose that $F$ follows the well-known exponential distribution $F(r)=1-e^{-r / \mu}$ with $r \in[0, \infty)$ which has density $f(r)=(1 / \mu) e^{-r / \mu}$ and a constant inverse hazard rate, $h(r)=\mu$. Setting this value into expressions (5) and (7), we find that $p^{f}=c_{H}+\mu$ and $p^{a}=\lambda\left(c_{H}+\mu\right)=\lambda p^{f}$. So, ignoring the participation constraint, asymmetric information simply entails a rescaling of the price with respect to the full information case. Moreover, it is clear from expressions (6) and (8) that $p^{a} / \lambda=p^{f}$ implies that $\lambda^{a}=\lambda^{f}$. To find the exact value of this probability, we take the same investment cost function as in our initial setting: $I(\lambda)=$ $(k / 2) \lambda^{2}$. (This function does not satisfy $\lim _{\lambda \rightarrow 1} I^{\prime}(\lambda)=\infty$ but works well nevertheless.) Hence, $I^{\prime}(\lambda)=k \lambda$ and $I^{\prime^{-1}}(\lambda)=\lambda / k$. As $f\left(p^{f}\right) h\left(p^{f}\right)^{2}=$ $(1 / \mu) e^{-p^{f} / \mu} \times \mu^{2}$, we have

$$
\lambda^{a}=\lambda^{f}=\frac{1}{k} \mu e^{-\frac{1}{\mu}\left(c_{H}+\mu\right)} .
$$

The participation constraint is binding if $p^{a}=\lambda^{a}\left(c_{H}+\mu\right)<c_{H}$, which is equivalent to

$$
\lambda^{a}<\frac{c_{H}}{c_{H}+\mu} \equiv \tilde{\lambda}
$$

Using the value of $\lambda^{a}$, we can rewrite the latter condition as

$$
\frac{1}{k} \mu e^{-\frac{1}{\mu}\left(c_{H}+\mu\right)}<\frac{c_{H}}{c_{H}+\mu} \Leftrightarrow k>\frac{c_{H}+\mu}{c_{H}} \mu e^{-\frac{1}{\mu}\left(c_{H}+\mu\right)} \equiv k_{2} .
$$

The alternative for the firm is to choose $\lambda=\tilde{\lambda}$ and $p=c_{H}$. The expected profit is then computed as

$$
\begin{aligned}
\pi^{a}-I\left(\frac{c_{H}}{c_{H}+\mu}\right) & =\left[1-F\left(c_{H}+\mu\right)\right]\left(c_{H}-\frac{c_{H}}{c_{H}+\mu} c_{H}\right)-I\left(\frac{c_{H}}{c_{H}+\mu}\right) \\
& =\frac{c_{H}}{c_{H}+\mu}\left[\mu e^{-\frac{1}{\mu}\left(c_{H}+\mu\right)}-\frac{k}{2} \frac{c_{H}}{c_{H}+\mu}\right] .
\end{aligned}
$$

Hence, investing up to $\tilde{\lambda}$ is profitable as long as

$$
\pi^{a}-I(\tilde{\lambda}) \geq 0 \Longleftrightarrow k \leq 2 \frac{c_{H}+\mu}{c_{H}} \mu e^{-\frac{1}{\mu}\left(c_{H}+\mu\right)}=2 k_{2} .
$$


As $\tilde{\lambda}>\lambda^{a}=\lambda^{f}$, we conclude that for $k_{2}<k \leq 2 k_{2}$, the firm overinvests relative to the full information case to avoid adverse selection.

As in Subsection 4.2, the firm's overinvestment may improve welfare with respect to the full information case. In our example, the indifferent consumer has the same identity under full and under asymmetric information: $p^{f}=$ $p^{a} / \lambda^{a}=c_{H}+\mu$. The expected total net surplus is thus given by the same expression in the two cases: $S(\lambda)=\lambda K-(k / 2) \lambda^{2}$, where (setting $\bar{r}=\infty$ )

$$
K=\int_{c_{H}+\mu}^{\infty}\left(r-c_{H}\right) \frac{1}{\mu} e^{-\frac{r}{\mu}} d r=2 \mu e^{-\frac{1}{\mu}\left(c_{H}+\mu\right)} .
$$

The function $S(\lambda)$ increases up to $\lambda=K / k$ and decreases afterward. Hence, as $\tilde{\lambda}>\lambda^{f}$, a sufficient condition for $S(\tilde{\lambda})>S\left(\lambda^{f}\right)$ is $\tilde{\lambda}<K / k$, which is equivalent to

$$
k<\frac{c_{H}+\mu}{c_{H}}\left[2 \mu e^{-\frac{1}{\mu}\left(c_{H}+\mu\right)}\right]=2 k_{2} .
$$

Hence, for $k_{2}<k \leq 2 k_{2}$ asymmetric information entails a welfare-improving increase in investment relative to the full information case.

\section{Conclusion}

We have provided a simple model that shows that asymmetric information about product quality may increase the incentives to provide higher quality due to what we have coined the adverse selection and the efficiency effect. Our result obtains in situations where firms have the possibility to make a risky and observable investment to increase the average quality (reliability) of their products. An example of such investments could be the effort to obtain the ISO 9000 certification for the firm's quality management system. Although consumers do not observe the realization of quality, they observe how much the firm has invested and, thereby, infer useful information about the expected quality on the market. Knowing this, a firm producing high quality may overinvest in the quality or reliability of its product to convince consumers that high quality is indeed very likely to be put on the market; this avoids the lemons problem. Also, if selling low quality has a negative social value, the firm may want to reduce the probability of low quality realization compared to the full-information world, because under full infor- 
mation low quality would not be put on the market, whereas in an adverse selection environment low quality is always offered.

We have thus identified two simple reasons for overinvestment in quality under asymmetric information. We analyzed in detail a particularly simple model that provides explicit solutions; however, the logic of our argument applies more generally. As we have shown in the extension section, our arguments remain valid (i) if we introduce a moral hazard problem after the investment stage and introduce quality-dependent outside options, (ii) if consumers have some bargaining power so that the firm cannot extract the full surplus, and (iii) if consumers have heterogeneous valuations for highquality products so that the resulting demand curve is downward sloping. Our overinvestment result is relative to the full information case. As we have illustrated in extensions (ii) and (iii), if the investment under full information is less than the welfare optimum, public policy that removes the asymmetric information problem may be welfare-decreasing.

An interesting extension is to embed our model into a setting with different firm types so that the issue of signaling arises. One such setting would be to allow for a share of informed consumers (who directly observe product quality, e.g., by reading consumer reports) and a share of consumers who only observe the investment level. Suppose there are two types of firms, which differ by their technology to convert investments in success probability. Focussing on separating equilibria, we expect that for a set of parameters, equilibria exist in which a firm of the less efficient type does not invest (because of adverse selection) whereas more efficient firms overinvest. In this case, our adverse selection effect comes again into play: the firm has to invest a sufficient amount in order to convince consumers that high-quality firms stay in the market. Due to the presence of informed consumers, a firm with a less efficient technology does not have an incentive to mimic the firm with a more efficient technology. Hence, the investment level contains additional information because of its signaling role: consumers correctly learn the type of the firm through the investment level. Signaling here is costless in the sense that the firm chooses the same investment level independent of whether consumers observe the firm's type. This suggests that our arguments are also relevant in signaling environments. 
Another interesting extension concerns information disclosure. In our model, the firm fully discloses its information at the investment stage so that consumers learn expected quality. Our investment cost function includes any advertising costs that are needed for full disclosure (at the investment stage) because otherwise, the investment is of no value to the firm in our benchmark model. Our overinvestment results therefore critically rely on the firm's ability to use directly informative advertising to truthfully communicate information to consumers. This suggests that laws against deceptive advertising can stimulate investment incentives. However, firms may not be able to communicate realized quality to consumers. In the language of the economics literature on advertising, consumers learn their expected match value but remain uncertain until after purchase about their realized match value. ${ }^{20}$ Future work may want to take a closer look at the interaction of investment and advertising decision under asymmetric information.

\footnotetext{
${ }^{20}$ On advertising as information about match value, see Meurer and Stahl (1994) and Anderson and Renault (2006).
} 


\section{References}

[1] Akerlof, George (1970), The Market for Lemons: Qualitative Uncertainty and the Market Mechanism, Quarterly Journal of Economics $84,488-500$.

[2] Anderson, Simon P. and Régis Renault (2006), Advertising Content, American Economic Review 96, 93-113.

[3] Anderson, Shannon W., J. Daniel Daly and Marilyn F. Johnson (1999), Why Firms Seek ISO 9000 Certification: Regulatory Compliance or Competitive Advantage? Production and Operations Management 8, $28-43$.

[4] Bagnoli, Mark. and Ted Bergstrom (2005), Log-Concave Probability and its Applications, Economic Theory 26, 445-469.

[5] Biglaiser, Gary (1993), Middlemen as Experts, Rand Journal of Economics 24, 212-223.

[6] Cole, Robert E. (1998), Learning from the Quality Movement: What Did and What Didn't Happen? California Management Review 41, 43-73.

[7] Creane, Anthony (2007), Investment and Latent Adverse Selection, mimeo.

[8] de Meza, David and David C. Webb (1987), Too Much Investment: A Problem of Asymmetric Information, Quarterly Journal of Economics 102, 281-292.

[9] Daughety, Andrew and Jennifer Reinganum (1995), Product Safety: Liability, R\&D, and Signaling, American Economic Review 85, 11871206.

[10] Daughety, Andrew and Jennifer Reinganum (2005), Secrecy and Safety, American Economic Review 95, 1074-1091.

[11] Daughety, Andrew and Jennifer Reinganum (2007), Communicating Quality: A Unified Model of Disclosure and Signaling, mimeo. 
[12] Grossman, Sanford J. (1981), The Information Role of Warranties and Private Disclosure about Product Quality, Journal of Law and Economics $24,461-83$.

[13] Kessler, Anke (2001), Revisiting the Lemons Market, International Economic Review 42, 25-41.

[14] Klein, Benjamin and Keith Leffler (1981), The Role of Market Forces in Assuring Contractual Performance, Journal of Political Economy 89, 615-641.

[15] Leland, Hayne E. (1979), Quacks, Lemons, and Licensing: A Theory of Minimum Quality Standards, Journal of Political Economy 87, 13281346 .

[16] Lensink, Robert and Elmer Sterken (2001), Asymmetric Information, Option to Wait to Invest and the Optimal Level of Investment, Journal of Public Economics 79, 365-374.

[17] Levin, Jonathan (2001), Information and the Market for Lemons, Rand Journal of Economics 32, 657-666.

[18] Meurer, Michael J. and Stahl, Dale O., II. (1994), Informative Advertising and Product Match, International Journal of Industrial Organization 12, 1-19.

[19] Milgrom, Paul and John Roberts (1986), Price and Advertising Signals of Product Quality, Journal of Political Economy 94, 796-821.

[20] Nelson, Philip (1974), Advertising as Information, Journal of Political Economy 82, 729-54.

[21] Shieh, Shiou (1993), Incentives for Cost-Reducing Investment in a Signalling Model of Product Quality, Rand Journal of Economics 24, 466477 .

[22] Spence, Michael (1973), Job Market Signaling, Quarterly Journal of Economics 87, 355-374. 
[23] Tadelis, Steven (1999), What's in a Name? Reputation as a Tradeable Asset, American Economic Review 89, 548-563. 


\section{CESifo Working Paper Series}

for full list see www.cesifo-group.org/wp

(address: Poschingerstr. 5, 81679 Munich, Germany, office@cesifo.de)

2557 Christian Keuschnigg, Corporate Taxation and the Welfare State, February 2009

2558 Marcel Gérard, Hubert Jayet and Sonia Paty, Tax Interactions among Belgian Municipalities: Does Language Matter?, February 2009

2559 António Afonso and Christophe Rault, Budgetary and External Imbalances Relationship: A Panel Data Diagnostic, February 2009

2560 Stefan Krasa and Mattias Polborn, Political Competition between Differentiated Candidates, February 2009

2561 Carsten Hefeker, Taxation, Corruption and the Exchange Rate Regime, February 2009

2562 Jiahua Che and Gerald Willmann, The Economics of a Multilateral Investment Agreement, February 2009

2563 Scott Alan Carson, Demographic, Residential, and Socioeconomic Effects on the Distribution of $19^{\text {th }}$ Century US White Statures, February 2009

2564 Philipp Harms, Oliver Lorz and Dieter Urban, Offshoring along the Production Chain, February 2009

2565 Patricia Apps, Ngo Van Long and Ray Rees, Optimal Piecewise Linear Income Taxation, February 2009

2566 John Whalley and Shunming Zhang, On the Arbitrariness of Consumption, February 2009

2567 Marie-Louise Leroux, Endogenous Differential Mortality, Non-Contractible Effort and Non Linear Taxation, March 2009

2568 Joanna Bęza-Bojanowska and Ronald MacDonald, The Behavioural Zloty/Euro Equilibrium Exchange Rate, March 2009

2569 Bart Cockx and Matteo Picchio, Are Short-Lived Jobs Stepping Stones to Long-Lasting Jobs?, March 2009

2570 David Card, Jochen Kluve and Andrea Weber, Active Labor Market Policy Evaluations: A Meta-analysis, March 2009

2571 Frederick van der Ploeg and Anthony J. Venables, Harnessing Windfall Revenues: Optimal Policies for Resource-Rich Developing Economies, March 2009

2572 Ondřej Schneider, Reforming Pensions in Europe: Economic Fundamentals and Political Factors, March 2009 
2573 Jo Thori Lind, Karl Ove Moene and Fredrik Willumsen, Opium for the Masses? Conflict-Induced Narcotics Production in Afghanistan, March 2009

2574 Silvia Marchesi, Laura Sabani and Axel Dreher, Agency and Communication in IMF Conditional Lending: Theory and Empirical Evidence, March 2009

2575 Carlo Altavilla and Matteo Ciccarelli, The Effects of Monetary Policy on Unemployment Dynamics under Model Uncertainty - Evidence from the US and the Euro Area, March 2009

2576 Falko Fecht, Kjell G. Nyborg and Jörg Rocholl, The Price of Liquidity: Bank Characteristics and Market Conditions, March 2009

2577 Giorgio Bellettini and Filippo Taddei, Real Estate Prices and the Importance of Bequest Taxation, March 2009

2578 Annette Bergemann and Regina T. Riphahn, Female Labor Supply and Parental Leave Benefits - The Causal Effect of Paying Higher Transfers for a Shorter Period of Time, March 2009

2579 Thomas Eichner and Rüdiger Pethig, EU-Type Carbon Emissions Trade and the Distributional Impact of Overlapping Emissions Taxes, March 2009

2580 Antonios Antypas, Guglielmo Maria Caporale, Nikolaos Kourogenis and Nikitas Pittis, Selectivity, Market Timing and the Morningstar Star-Rating System, March 2009

2581 António Afonso and Christophe Rault, Bootstrap Panel Granger-Causality between Government Budget and External Deficits for the EU, March 2009

2582 Bernd Süssmuth, Malte Heyne and Wolfgang Maennig, Induced Civic Pride and Integration, March 2009

2583 Martin Peitz and Markus Reisinger, Indirect Taxation in Vertical Oligopoly, March 2009

2584 Petra M. Geraats, Trends in Monetary Policy Transparency, March 2009

2585 Johannes Abeler, Armin Falk, Lorenz Götte and David Huffman, Reference Points and Effort Provision, March 2009

2586 Wolfram F. Richter, Taxing Education in Ramsey’s Tradition, March 2009

2587 Yin-Wong Cheung, Menzie D. Chinn and Eiji Fujii, China's Current Account and Exchange Rate, March 2009

2588 Alexander Haupt and Silke Uebelmesser, Voting on Labour-Market Integration and Education Policy when Citizens Differ in Mobility and Ability, March 2009

2589 Hans Jarle Kind, Marko Koethenbuerger and Guttorm Schjelderup, Should UtilityReducing Media Advertising be Taxed?, March 2009 
2590 Alessandro Cigno, How to Avoid a Pension Crisis: A Question of Intelligent System Design, March 2009

2591 Helmut Lütkepohl and Fang $\mathrm{Xu}$, The Role of the Log Transformation in Forecasting Economic Variables, March 2009

2592 Rainald Borck, Hyun-Ju Koh and Michael Pflüger, Inefficient Lock-in and Subsidy Competition, March 2009

2593 Paolo M. Panteghini, On the Equivalence between Labor and Consumption Taxation, March 2009

2594 Bruno S. Frey, Economists in the PITS?, March 2009

2595 Natalie Chen and Dennis Novy, International Trade Integration: A Disaggregated Approach, March 2009

2596 Frédérique Bec and Christian Gollier, Term Structure and Cyclicity of Value-at-Risk: Consequences for the Solvency Capital Requirement, March 2009

2597 Carsten Eckel, International Trade and Retailing, March 2009

2598 Gianni De Nicolò and Iryna Ivaschenko, Global Liquidity, Risk Premiums and Growth Opportunities, March 2009

2599 Jay Pil Choi and Heiko Gerlach, International Antitrust Enforcement and Multi-Market Contact, March 2009

2600 Massimo Bordignon and Guido Tabellini, Moderating Political Extremism: Single Round vs Runoff Elections under Plurality Rule, April 2009

2601 Ana B. Ania and Andreas Wagener, The Open Method of Coordination (OMC) as an Evolutionary Learning Process, April 2009

2602 Simon Gächter, Daniele Nosenzo, Elke Renner and Martin Sefton, Sequential versus Simultaneous Contributions to Public Goods: Experimental Evidence, April 2009

2603 Philippe Jehiel and Andrew Lilico, Smoking Today and Stopping Tomorrow: A Limited Foresight Perspective, April 2009

2604 Andreas Knabe, Steffen Rätzel, Ronnie Schöb and Joachim Weimann, Dissatisfied with Life, but Having a Good Day: Time-Use and Well-Being of the Unemployed, April 2009

2605 David Bartolini and Raffaella Santolini, Fiscal Rules and the Opportunistic Behaviour of the Incumbent Politician: Evidence from Italian Municipalities, April 2009

2606 Erkki Koskela and Jan König, Can Profit Sharing Lower Flexible Outsourcing? A Note, April 2009 
2607 Michel Beine, Frédéric Docquier and Çağlar Özden, Diasporas, April 2009

2608 Gerd Ronning and Hans Schneeweiss, Panel Regression with Random Noise, April 2009

2609 Adam S. Booij, Bernard M.S. van Praag and Gijs van de Kuilen, A Parametric Analysis of Prospect Theory's Functionals for the General Population, April 2009

2610 Jeffrey R. Brown, Julia Lynn Coronado and Don Fullerton, Is Social Security Part of the Social Safety Net?, April 2009

2611 Ali Bayar and Bram Smeets, Economic, Political and Institutional Determinants of Budget Deficits in the European Union, April 2009

2612 Balázs Égert, The Impact of Monetary and Commodity Fundamentals, Macro News and Central Bank Communication on the Exchange Rate: Evidence from South Africa, April 2009

2613 Michael Melvin, Christian Saborowski, Michael Sager and Mark P. Taylor, Bank of England Interest Rate Announcements and the Foreign Exchange Market, April 2009

2614 Marie-Louise Leroux, Pierre Pestieau and Gregory Ponthiere, Should we Subsidize Longevity?, April 2009

2615 Ronald MacDonald, Lukas Menkhoff and Rafael R. Rebitzky, Exchange Rate Forecasters' Performance: Evidence of Skill?, April 2009

2616 Frederick van der Ploeg and Steven Poelhekke, The Volatility Curse: Revisiting the Paradox of Plenty, April 2009

2617 Axel Dreher, Peter Nunnenkamp, Hannes Öhler and Johannes Weisser, Acting Autonomously or Mimicking the State and Peers? A Panel Tobit Analysis of Financial Dependence and Aid Allocation by Swiss NGOs, April 2009

2618 Guglielmo Maria Caporale, Roman Matousek and Chris Stewart, Rating Assignments: Lessons from International Banks, April 2009

2619 Paul Belleflamme and Martin Peitz, Asymmetric Information and Overinvestment in Quality, April 2009 